\title{
Entrainment to non-24-h days and gestation length of golden hamsters
}

\author{
Marie S. Carmichael and I. Zucker \\ Department of Psychology, University of California, Berkeley, California 94720, U.S.A.
}

\begin{abstract}
Summary. Hamsters were entrained to a 23 -h or a 24-h photoperiod, each with $14 \mathrm{~h}$ of light per cycle. Gestation length did not differ significantly for animals in the two photoperiods ( 378 and $383 \mathrm{~h}$ ), and it is concluded that the duration of hamster pregnancy is not measured in circadian cycles.
\end{abstract}

\section{Introduction}

Precision in timing the duration of pregnancy is biologically adaptive. Post-implantation gestation length is subject to relatively small intraspecific variation (Short, 1974). In hamsters, implantation occurs on Day 5 and parturition on Day 16 after insemination (Boyer, 1953); the standard deviation of gestation length is 1.9-3.6 h (Siegel \& Greenwald, 1975; Vickery, 1979). Precise timing of biological processes is often mediated by a circadian clock, but the role of a circadian system, if any, in timing the duration of gestation remains poorly understood. The present experiment tested the hypothesis that the duration of hamster gestation is measured in circadian cycles. If this assumption is valid, the 16-day gestation length of hamsters entrained to 24-h days should be shortened by $16 \mathrm{~h}$ in females entrained to 23-h days throughout pregnancy. Other factors determining the timing of parturition may be uterine distension produced by the fetuses (Csapo \& Lloyd-Jacobs, 1962) and/or a hormonal signal governed by the maturation of the fetal pituitary-adrenal-placental axis (Lincoln \& Porter, 1976), in which case days shorter than 24 h would have little or no effect on the duration of gestation.

\section{Materials and Methods}

Hamsters (Mesocricetus auratus) were maintained from birth in $14 \mathrm{~h}$ light :9 h dark, 14L:9D $(\mathrm{N}=$ 12) and 14L:10D $(\mathrm{N}=10)$ photoperiods $(\mathrm{T}=23 \mathrm{~h}$ and $\mathrm{T}=24 \mathrm{~h}$, respectively). At $4 \cdot 5$ months of age, the animals were placed in light-proof ventilated cabinets, illuminated with fluorescent light tubes programmed for $\mathrm{T}=23 \mathrm{~h}$ or $\mathrm{T}=24 \mathrm{~h}$. Hamsters were housed individually in cages equipped with running wheels.

Locomotor activity was monitored separately for each hamster on an event recorder (see Carmichael, Nelson \& Zucker, 1981). Two or more consecutive oestrous cycles were confirmed for each female before mating. Each female was allowed to mate for $30 \mathrm{~min}$ to a criterion of at least 5 ejaculations in tests, in the home cage of a male, beginning $3 \mathrm{~h}$ after onset of oestrus, which was determined behaviourally (see Carmichael et al., 1981). Females were inspected for birth of litters at least once every $4 \mathrm{~h}$ beginning $372 \mathrm{~h}$ after mating.

Data were analysed with Student's two-tailed $t$ tests and with correlation tests. The mean period 
$(\bar{\tau})$ of the activity rhythm was calculated from the times of consecutive wheel-running onsets spanning 12 or more days.

\section{Results}

The duration of pregnancy of females entrained to $\mathrm{T}=23 \mathrm{~h}$ was significantly $(P<0.001)$ longer than predicted by the circadian hypothesis; i.e. mean \pm s.d. $=378.4 \pm 3.7 \mathrm{~h}$ compared with $368 \mathrm{~h}$ $(16$ days $\times 23 \mathrm{~h})$. There were no reliable differences in the duration of pregnancy of females entrained to $\mathrm{T}=23 \mathrm{~h}(378.4 \pm 3.7 \mathrm{~h})$ and $\mathrm{T}=24 \mathrm{~h}(382.9 \pm 6.7 \mathrm{~h}, P>0.10)$. Eleven of the 12 females maintained since birth in $\mathrm{T}=23 \mathrm{~h}$ remained entrained to this cycle before mating $(\bar{\tau} \pm$ s.d. $=23.01 \pm 0.08 \mathrm{~h})$ and throughout pregnancy $(\bar{\tau} \pm$ s.d. $=23.07 \pm 0.19 \mathrm{~h})$, although wheel running was reduced during gestation $(P<0.05)$. Running onsets of dams placed into constant darkness after litters were weaned confirmed entrainment to $\mathrm{T}=23 \mathrm{~h}$.

Weight gain data suggest that all mated females were successfully impregnated. Two animals in each group failed to give birth to live young; 3 of these females apparently resorbed their fetuses between Days 6 and 12 of gestation and the 4th female produced dead offspring $378 \mathrm{~h}$ after mating.

Gestation length did not correlate significantly $(P>0.20)$ with $\bar{\tau}$ for Days $1-5$ after mating (preimplantation phase), Days 6-16 of gestation, or the entire duration of pregnancy (Days 1-16).

The interval between light onset and mating ( $3 \mathrm{~h}$ after onset of oestrus) was greater for hamsters in $\mathrm{T}=23 \mathrm{~h}$ than for those in $\mathrm{T}=24 \mathrm{~h}$ (mean \pm s.e. $=19.08 \pm 0.45$ compared with $16.21 \pm 0.88 \mathrm{~h}$, $P<0.01$ ). The interval between light onset and parturition also differed (mean \pm s.e. $=6.62 \pm$ $1.16 \mathrm{~h}$ in $\mathrm{T}=23 \mathrm{~h}$ and $13.02 \pm 2.52 \mathrm{~h}$ in $\mathrm{T}=24 \mathrm{~h} ; P<0.02)$. The intervals between light onset and mating and light onset and parturition did not differ for hamsters in $\mathrm{T}=24 \mathrm{~h}(P>0 \cdot 20)$, but there was a significant difference in these values $(P<0.001)$ for hamsters in $\mathrm{T}=23 \mathrm{~h}$.

\section{Discussion}

Pregnancy duration did not differ in hamsters entrained to $\mathrm{T}=23 \mathrm{~h}$ and $\mathrm{T}=24 \mathrm{~h}$ days, indicating that a circadian clock does not substantially affect the duration of hamster gestation. Davis \& Menaker (1981) and Lanman \& Seidman (1977) arrived at a similar conclusion from their studies of mice.

If a circadian clock determines the interval to implantation (Days 1-5) but does not control the duration of gestation after implantation (Days 6-16), pregnant hamsters entrained to a $\mathrm{T}=23 \mathrm{~h}$ photoperiod would be expected to undergo parturition $5 \mathrm{~h}$ earlier than hamsters entrained to a $\mathrm{T}=$ $24 \mathrm{~h}$ photoperiod. Although there was a mean reduction of $4.5 \mathrm{~h}$ in gestation length in hamsters housed in $\mathrm{T}=23 \mathrm{~h}$, the correlation between the period of the circadian activity rhythm during Days 1-5 of pregnancy and the duration of gestation was not significant. We tentatively conclude that the circadian mechanism timing the daily activity rhythm does not control the timing of implantation.

In accordance with circadian-rhythm theory, the interval between light onset and onset of oestrus was increased significantly for hamsters entrained to $\mathrm{T}=23 \mathrm{~h}$ (see Pittendrigh \& Daan, 1976; Carmichael et al., 1981). In contrast, the interval between light onset and parturition was significantly decreased. The timing of parturition in hamsters does not appear to be influenced by photoperiodic modulation of the circadian system but is more probably a fixed function of the hour of insemination or fertilization.

This research was supported by USPHS grant HD-03982 and by National Service Award 5-T 32 MH 15860-02. We thank Randy Nelson, Darlene Frost, Barbara Ries, Kimberly Pelz, Damian Carmichael and Margaret Hamilton for assistance. 


\section{References}

Boyer, C.C. (1953) The chronology of development for the golden hamster. $J$. Morph. 92, 1-33.

Carmichael, M.S., Nelson, R.J. \& Zucker, I. (1981) Hamster activity and estrous cycles: Control by a single versus multiple circadian oscillator(s). Proc. natn. Acad. Sci. U.S.A. 78, 7830-7834.

Caspo, A.I. \& Lloyd-Jacobs, M.A. (1962) Placenta, uterine volume, and the control of the pregnant uterus in rabbits. Am. J. Obstet. Gynec. 83, 1073.

Davis, F.C. \& Menaker, M. (1981) Development of the mouse circadian pacemaker: Independence from environmental cycles. J. comp. Physiol. 143, 527-539.

Lanman, J.T. \& Seidman, L. (1977) Length of gestation in mice under a 21-h day. Biol. Reprod. 17, 224-227.

Lincoln, D.W. \& Porter, D.G (1976) Timing of the photoperiod and the hour of birth in rats. Nature, Lond. 260, 780-781.
Pittendrigh, C.S. \& Daan, S. (1976) A functional analysis of circadian pacemakers in nocturnal rodents. IV. Entrainment: Pacemaker as clock. J. comp. Physiol. 106, 291-331.

Short, R.V. (1974) Rhythms of ovulation. In Chronobiological Aspects of Endocrinology, pp. 221-228. Eds J. Aschoff, F. Ceresa \& F. Halberg. Schattauer, Stuttgart.

Siegel, H.I. \& Greenwald, G.S. (1975) Prepartum onset of maternal behavior in hamsters and the effects of estrogen and progesterone. Horm. Behav. 6, 237-245.

Vickery, B. (1979) Prolongation of gestation in the rat and hamster by naproxen. Prostagl. Med. 2, 325-335.

Received 15 April 1982 